\title{
A RESEARCH ON PROJECT PERFORMANCE MEASUREMENT BY THE METHOD OF EARNED VALUE ANALYSIS*
}

\author{
DOI: 10.17261/Pressacademia.2021.1398 \\ RJBM- V.8-ISS.2-2021(2)-62-72 \\ Halil Savas ${ }^{1}, Z_{\text {Zafer Duran }}^{2 * *}$ \\ ${ }^{1}$ Pamukkale University, Faculty of Economics and Administrative Sciences, Denizli, Turkey \\ hsavas@pau.edu.tr, ORCID: 0000-0001-7942-5527 \\ ${ }^{2}$ Alanya Alaaddin Keykubat University, Gazipasa MRB Vocational School, Antalya, Turkey \\ zafer.duran@alanya.edu.tr , ORCID: 0000-0002-7227-4196
}

\begin{tabular}{l}
\hline Date Received: March 19, $2021 \quad$ Date Accepted: May 29, 2021 open access \\
\hline To cite this document \\
Savas, H., Duran, Z., (2021). A research on project performance measurement by the method of earned value analysis. Research Journal of Business \\
and Management (RJBM), 8(2), 62-72. \\
Permanent link to this document: http://doi.org/10.17261/Pressacademia.2021.1398 \\
Copyright: Published by PressAcademia and limited licensed re-use rights only. \\
\hline
\end{tabular}

\section{ABSTRACT}

Purpose - The purpose of this paper is to examine EVA method and to reveal the perspectives of the managers in project-based sectors regarding project management issues and EVA method.

Methodology - Primary data were used in this study. Data was collected through an online survey from 456 participants who manage projects in the business world.

Findings- A significant difference was found between two groups as those who use EVA and those who do not, in terms of the performance criteria of reaching the milestones of the projects on time and completing the projects on time.

Conclusion- In this study, it was seen that EVA offers significant opportunities for project-oriented businesses. However, the fact that the EVA method does not consider the risks and uncertainties is the most serious problem. Studies should be done to solve this problem, and the EVA should be made a more effective method.

Keywords: Earned value analysis, project management, project performance metrics, project management trends JEL Codes: M10, M11, C49

\section{INTRODUCTION}

Projects are those that consist of a sequence of activities made to achieve a goal, which have a complex start-up and finish dates, and which require efficient use of resources. This requires that projects be managed based on budget, time, and scope constraints.

The most important activity of the project management process is the measurement and evaluation of the performance of the project. The performance of a project demonstrates how well the project has progressed towards its objectives. For this reason, it is possible to measure the performance of a project with the project plans being implemented. If performance is the first measure of correct measurement, plan the project in line with realistic goals (Navon \& Sacks, 2007).

Project performance gives important clues about the success of the project carried out by project stakeholders. Measuring the performance of a project in this direction is a prerequisite for running the project. However, the performance of each project must be measured in the direction of the project's specific goals and objectives.

Due to the complexity of the project both from project performance measurement and from planning mistakes, the actual success of the project can never be determined due to the method used. But with good measurements, it is possible to obtain the closest results (Kerzner, 2006)

\footnotetext{
${ }^{*}$ This article is adapted from the master's thesis called Earned value analysis as a project performance measurement system and a research.

** Corresponding author
} 
EVA is a methodology used to measure and communicate the real physical progress of a project and to integrate the three critical elements of project management (scope, time, and cost management) (Vandevoorde \& Vanhoucke, 2006). This is a proactive project performance measurement tool. It also produces variance and performance indices for project costs and schedules, and thus predicts project costs and schedules at completion, providing early indications of expected project performance results (Chen, Chen, \& Lin, 2016). By evaluating the methodology, cost, and schedule measure together, a project provides integrated information about both budget performance and schedule performance.

Traditional cost management uses a bivariate approach to measure project success - real cost and planned cost. For this reason, the actual cost calculated based on the initial assumption, which is used the planning stage of the project performance to be calculated at any stage, will not be an accurate reflection of actual success.

Therefore, a third variable called "earned value" is needed to measure actual accomplishment. Figure 1 depicts the variance comparison. The earned value system reduces subjectivity and provides a more objective performance measurement. The basic concept of establishing and maintaining a plan against which to measure actual accomplishment is one of the most fundamental management principles. Earned value is a practical tool to apply such a principle (Chen, 2008: 3).

\section{Figure 1: Traditional Cost Management vs. Earned Value}

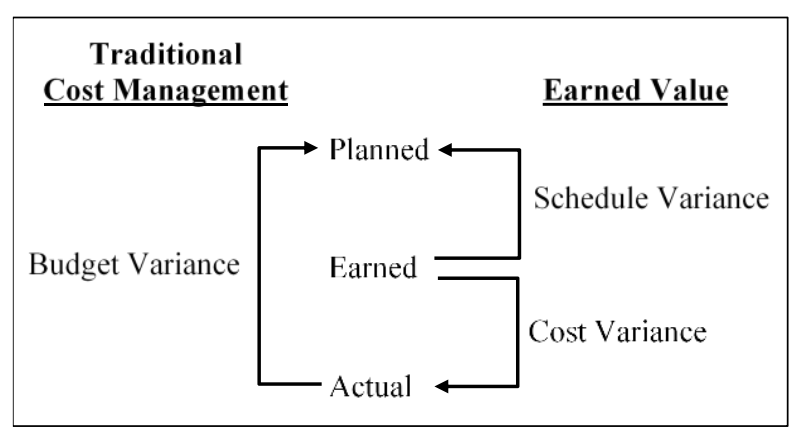

Source: Chen (2008, p.3)

This research was conducted to examine the project managers' perspectives on project success factors, the success levels of the projects they carried out, and their perspectives on EVA. In this context it consists of 4 parts: literature review, data and methodological approach, findings and discussions, and conclusion.

Within the scope of the research, the attached questionnaire was applied to the project managers and the current situation regarding the project methods and project successes that are widely used was tried to be revealed. In addition, the prevalence of EVA, which is a project performance management system based on project budget and schedule, and its effects on project success were examined. It is thought that the findings will provide significant benefits to researchers and project managers.

\section{LITERATURE REVIEW}

EVM is an objective management technique that is useful to measure the performance of a project and its progress. At the same time, it can be called Variance Analysis (Zhong \& Wang, 2011). It is a strong project performance technique because it can measure the time and cost performance of a project at the same time.

This method measures deviations of the plan comparing the data of current costs and time with estimated project indexes. These deviations show how suitable the project is to the plan. This way the method, allows the calculation of the performance of the project and at the same time allows correcting the performance (Anbari, 2003).

The foundation of EVM is based on U.S.A. air force studies to guide project contractors in the 1960s. Ever since this time this method has been used by several countries' ministries especially by the U.S.A for diverse big projects which had been bought (Taylor, 2006). Nowadays it is being used as an internal audit for management functions of projects with a complicated structure.

This method is calculating the costs and time performance indexes of projects. This way this method measures the planned performances of the project completion costs and the length of the project comparing to the actual values. Thus, the method can measure the most important elements: cost, timing, and the content performance of a project at the same time integrating project performance and productivity management. 
Considering all these aspects one can think that this method has a pro-active methodology structure. This pro-active structure allows the project managers to compensate for project deviations from the project performance expectations in each time.

This method uses the planned value, earned value, and actual cost parameters to evaluate the project performance. Using these parameters, this method is doing the performance measurement and with the outcomes, it blends the foreseen plans and creates the completion projection of the project (Bhosekar \& Vyas, 2012). The basic parameters of EVA are given in Figure 2, and it is briefly explained in the following paragraphs.

\section{Figure 2: Basic Parameters of Earned Value Analysis}

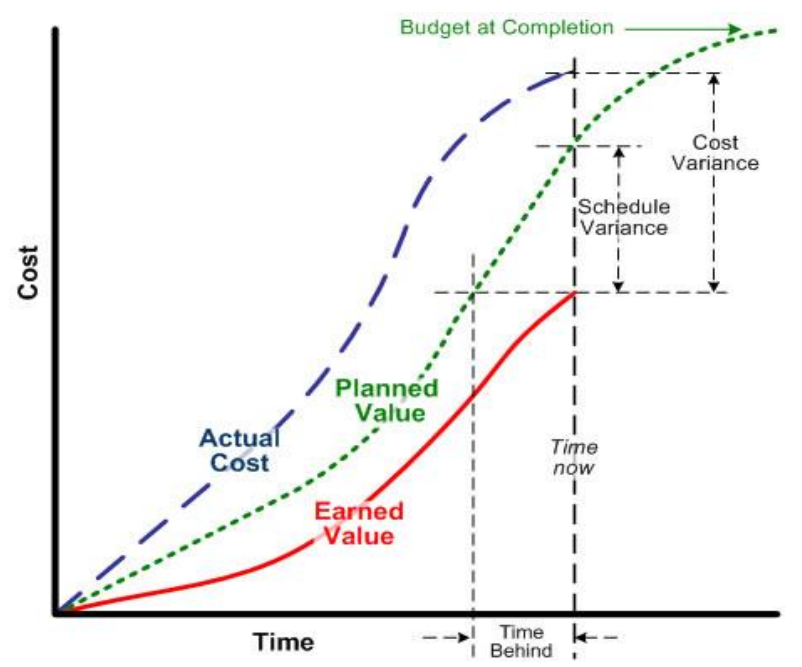

Source: https://www.projectemplates.com/earned-value-analysis-template/ Access date: September 04, 2020)

Planned Value (PV): It refers to the planned total cost of the works to be performed within a certain time. In other words, it is the budgeted cost of the work planned for a given time (Gupta, 2014).

Since the planned value will serve as a reference for the performance of the project, it is extremely important to accurately measure the performance of the project since it contains realistic data. Therefore, a very detailed planned value list should be created during the planning phase. Thus, the data will have a realistic value.

Earned Value (EV): It refers to the budgeted value of the completed project activities. In the calculation of the earned value, the projected costs of the completed works can be easily obtained when they have been previously determined. However, some activities may not be completed at the time of performance measurement. Although these activities are not completed, time and money values that correspond to the completion percentages of the activities should also be considered for these activities to reach the current state.

There are some earned value measurement methods such as milestones with weighted values, fixed formula, percent complete estimates, the combination of percent complete estimates \& milestones, equivalent units, and earned standards. The value earned should be calculated by choosing the appropriate method for the project being executed.

Actual Cost (AC): It expresses the real value of the completed activity. The internal and external source data used in calculating the actual cost must comply with the data used in the planning phase.

Earned value analysis is a method that provides information about the performance of the project by comparing the earned value compared to the planned value and the actual cost. Performance indicators of this method are known as deviations and indices regarding cost and schedule. These indicators are described below.

Cost Performance Index (CPI): It measures the value of the work completed compared to the actual cost spent. It is being calculated with this formula $\mathrm{CPI}=\mathrm{EV} / \mathrm{AC}$. If $\mathrm{CPI}=1$; activities fit the budget. If $\mathrm{CPI}>1$; spending is lower than expected. If $\mathrm{CPI}<1$; spending exceeded the budget.

Schedule Performance Index (SPI): It shows the pace of progress for a project. It is calculated with this formula SPI = EV/PV. The value obtained because of the calculation gives a clue as to whether the project can be completed in the planned time or not. If 
$\mathrm{SPI}=1$; activities continue in accordance with the schedule. If $\mathrm{SPI}>1$; activities are ahead of schedule. If $\mathrm{SPI}<1$; activities fall behind schedule.

Cost Variance (CV): It is simply the difference between what was budgeted for the work performed and what it actual cost. The formula is CV = EV - AC. It shows how far the project is from the planned budget.

Schedule Variance (SV): It shows the difference between the time needed for the accomplished activity and the time planned for the given activity. In other words, it determines whether a project is ahead of or behind schedule. SV is calculated with the following formula: SV = EV - PV. It shows how loyal it proceeds to the plan. All the above-mentioned concepts related to EVA are interrelated. This relationship is better understood through the graph. Figure 3 describes this relationship.

All the above-mentioned concepts related to EVA are interrelated. This relationship is better understood through the graph. Figure 3 describes this relationship.

Figure 3: Relation with each other of Basic Parameters of Earned Value Analysis

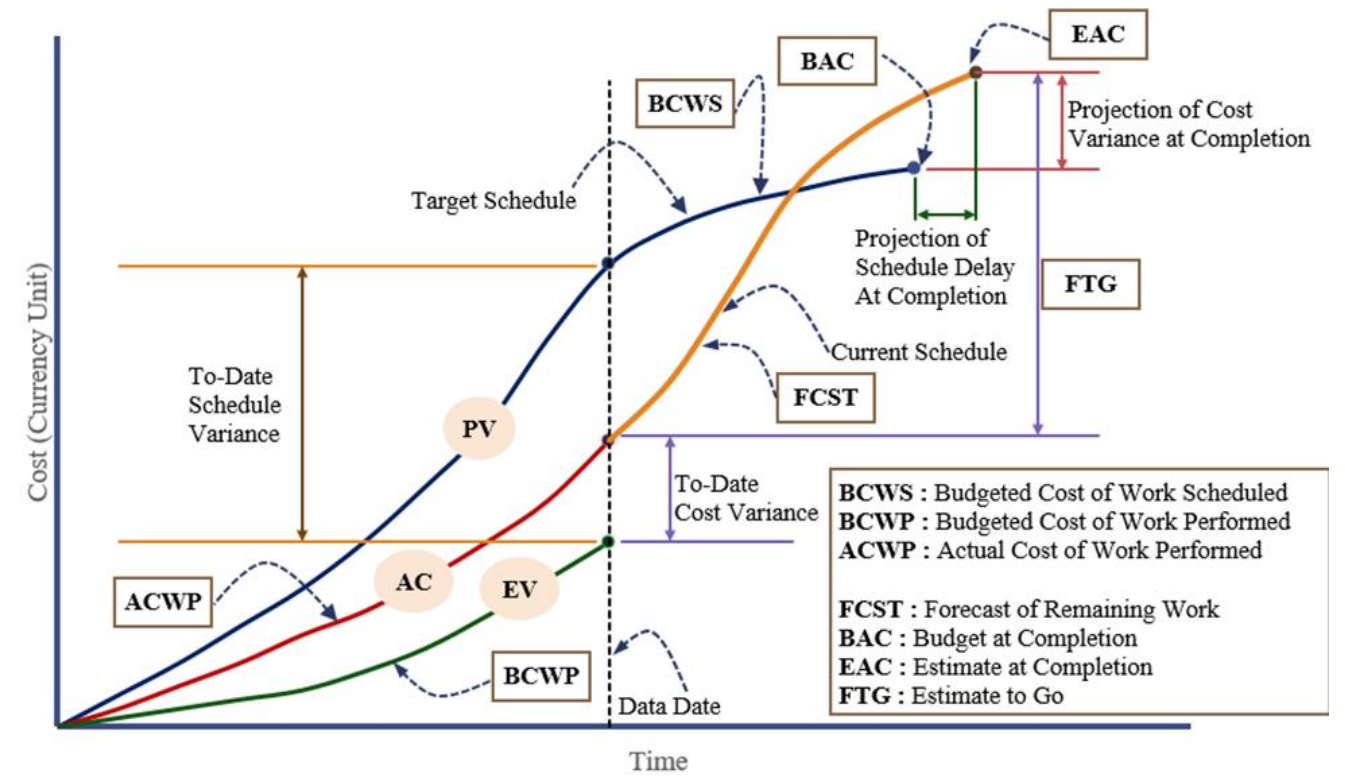

Note: Adapted from Sources: Zhong \& Wang, 2011, https://www.vertex42.com/ExcelTemplates/earned-value-management.html, and https://www.chambers.com.au/glossary/earned_value_management.php, Access date: October 05, 2020).

The planned value is accepted as the reference value in the EVM method. At any control, the cost and earned values are calculated based on this reference value. If there is a deviation from the planned value, the causes of this deviation should be investigated, and the problem should be solved.

\section{DATA AND METHODOLOGY}

This research has been realized to analyze the success of the projects which have been carried out in the last two years, the choice of project management tools, and the point of view of the organization's employees towards EVM who are involved in a projectbased environment.

The scope of the research is the employees of Turkish businesses that use the project management approach in their activities. The questionnaire that asked whether the participants use the project management approach is placed in the questionnaire form created accordingly, and the participants who do not use the project approach are not answered the other questions. In this context, the attached questionnaire was applied to the project managers with the convenience sampling method. 82 of the 538 participants of the survey in the research were excluded from the sample cluster with this method. The study was completed considering the responses of the remaining 456 participants.

The natural constraint of the research is the constraints arising from the fact that all the data obtained are responses to the questionnaire created and that the participants must evaluate their own project performance. These answers are conceptually and judicially open to mistakes. 
The unnatural constraints of the research are the constraints arising from the participants' sensitivity to give information of strategic importance.

Being able to collect data the questionnaire method has been preferred. The questionnaire has been done web-based to increase participation and to speed up the feedback. The questionnaire had been online for 67 days and during these time participants were invited per e-mail to answer the questionnaire.

\section{FINDINGS AND DISCUSSIONS}

The data obtained from the participants and the findings based on these data are given below, respectively. In this direction, first, the importance of traditional project constraints is given in Table 1.

\section{Table 1: Importance of Traditional Project Constraints}

\begin{tabular}{cccc}
\hline $\begin{array}{c}\text { Scale Rank } \\
\text { Order }\end{array}$ & \multicolumn{3}{c}{ Project Constraints and Frequencies } \\
\cline { 2 - 4 } & Budget & Time & Scope \\
\hline 1 & 3 & 1 & 2 \\
2 & 9 & 5 & 10 \\
3 & 39 & 25 & 57 \\
4 & 101 & 86 & 139 \\
5 & 304 & 339 & 248 \\
\hline
\end{tabular}

Table 1, as expected, shows that traditional project constraints are quite important by managers. The striking detail at this point is that the scope constraint is significantly less important than the other two constraints. This indicates that project managers can make more concessions in scope constraints than other constraints. In order to better explain this situation, the radar chart in Figure 4 was created.

\section{Figure 4: Traditional Project Constraints}

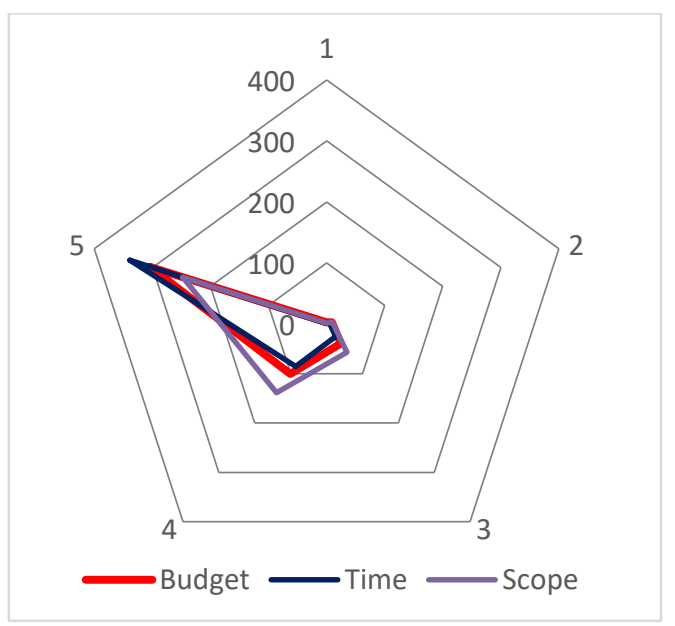

Figure 4 shows more clearly the tendency of project managers to make concessions to traditional constraints as a radar chart. Although traditional project constraints are equally important and cannot be compromised, today's competitive conditions are thought to be caused by project managers' tendency to compromise between constraints.

Projects are subjected to different performance measurements due to their types and sizes. This situation causes different metrics to be preferred according to the characteristics of the project in project performance measurement. These preferences of the project managers participating in the research are summarized in the table below. 
Table 2: Use of Project Performance Metrics

\begin{tabular}{lcc}
\hline Project Performance Metrics & f & \% \\
\hline Time & 392 & 97.03 \\
Cost & 370 & 91.58 \\
Customer satisfaction & 274 & 67.82 \\
Quality & 266 & 65.84 \\
Number of scope modification & 185 & 45.79 \\
Risk reduction activities & 145 & 35.89 \\
Rate of modification in requirements & 140 & 34.65 \\
Security considerations & 104 & 25.74 \\
Other & 14 & 3.47 \\
\hline
\end{tabular}

As far as one can see from Table 2 most of the participants are using time and cost metrics in performance measurement. This case is a coherent outcome of the importance of traditional project constraints with the data. It is assumed that less preference for metrics regarding the content is the outcome of tendencies in making a compromise in content constraint.

The tools used in project management have the features of supporting and supplementing each other. But just like in metrics, it differs from the characteristics of the managed project. Frequencies of the participants to use these tools is shown in Table 3.

Table 3: Use of Project Management Tools

\begin{tabular}{lcc}
\hline Project Management Tools & F & \% \\
\hline Project schedule & 406 & 89.04 \\
Project budget & 365 & 80.04 \\
Work breakdown structure & 315 & 69.08 \\
Cost analysis & 313 & 68.64 \\
Risk analysis & 301 & 66.01 \\
GANTT chart & 293 & 64.25 \\
Critical Path Method & 222 & 48.68 \\
SWOT analysis & 206 & 45.18 \\
Lessons learned & 191 & 41.89 \\
Earned value analysis & 183 & 40.13 \\
Diary problems & 156 & 34.21 \\
Break-Even analysis & 99 & 21.71 \\
PERT method & 89 & 19.52 \\
Slip chart & 48 & 10.53 \\
Delphi method & 37 & 8.11 \\
Other & 32 & 7.02 \\
None & 9 & 1.97 \\
\hline
\end{tabular}

When Table 3 is examined, it is seen that only nine participants do not use any project management tools, while the other majority use at least one project management tool. The project schedule is the most common project management tool with an $89.04 \%$ usage rate among these tools. Project budget, work breakdown structure, cost analysis, risk analysis, GANTT chart is also widely used tools. However, EVA is a preferred tool by a small number of participants. Considering the data about EVA's awareness of the participants, this state is considered too quiet surprising. The reason why participants are not using EVA is listed in Table 4. 
Table 4: Used Project Management Software

\begin{tabular}{lcc}
\hline \multicolumn{1}{c}{ Project Management Software } & F & \% \\
\hline Microsoft Project & 338 & 74.12 \\
Other Software & 132 & 28.95 \\
Primavera & 103 & 22.59 \\
None & 41 & 8.99 \\
HP Project and Portfolio Management (PPM) & 31 & 6.80 \\
VisionFlow & 17 & 3.73 \\
Redmine & 17 & 3.73 \\
Basecamp & 9 & 1.97 \\
Planbox Project Management & 7 & 1.54 \\
Workfront Project Management Software & 6 & 1.32 \\
Innotas PPM & 4 & 0.88 \\
\hline
\end{tabular}

As seen in Table 4, Microsoft Project software provides a superior advantage to other software in terms of being preferred. This is thought to be due to the fact that Microsoft company has a widespread marketing network and leads project management software. In addition, it is seen that $28.95 \%$ of the participants carry out their projects with software that is not known in the software market. This indicates that project managers tend to turn to more economical software to meet their needs.

Awareness of EVA, on the other hand, has a rather interesting distribution. This distribution is given in Table 5.

Table 5: Earned Value Analysis Awareness Level

\begin{tabular}{ccc}
\hline Awareness Level & $\mathbf{F}$ & \% \\
\hline 4 & 181 & 39.70 \\
5 & 85 & 18.64 \\
3 & 72 & 15.79 \\
1 & 65 & 14.25 \\
2 & 53 & 11.62 \\
\hline
\end{tabular}

When Table 5 is examined, it is understood that $58.34 \%$ of the participants are knowledgeable or expert about EVA. Considering the data on the tools used in the project management in Table 3, it is understood that some participants do not prefer to use the EVA although they are knowledgeable or expert about the EVA. This indicates that the EVA may have some negative aspects in practice. To examine these aspects, the participants who did not prefer to use EVA in their activities were asked the reasons for their preferences and the following results were obtained. In this context, the reasons why the project managers do not use EVA contain important clues. Table 6 shows the distribution of the project managers' reasons for not using EVA.

Table 6: Rationale for not using EVA

\begin{tabular}{lcc}
\hline Rationale & f & \% \\
\hline Customers have no such demand & 112 & 41.02 \\
Not having the necessary technical knowledge about the system & 74 & 27.10 \\
Top management does not support & 59 & 21.61 \\
The lack of a suitable system for the industry & 45 & 16.48 \\
Not wanting to change the current control system & 45 & 16.48 \\
Lack of technological infrastructure & 44 & 16.11 \\
It is not considered to work & 29 & 10.62 \\
The tediousness of collecting and processing data & 22 & 8.05 \\
The system has too many rules & 10 & 3.66 \\
It is a complicated system & 9 & 3.29 \\
It is a costly system & 4 & 1.46 \\
It is a failed system & 3 & 1.09 \\
Other reasons & 29 & 10.62 \\
\hline
\end{tabular}

As seen in Table 6, most of the reasons for not using the EVA are not the reasons for the structure of the method. The reasons arising from the structure of the system have a share of only $9.52 \%$. This shows that EVA is preferred less than other tools for subjective reasons rather than structural deficiencies. 
EVA offers significant advantages to project managers who use it. According to the participants who prefer EVA, the contributions of the method to the projects are given in Table 7.

\section{Table 7: Contributions by EVA}

\begin{tabular}{lcc}
\hline Contributions & f & \% \\
\hline Provides early-warning about cost & 128 & 69.95 \\
Integrates cost and schedule & 112 & 61.20 \\
Data from the analysis sheds light on similar projects & 107 & 58.47 \\
Offers valuable numerical data & 100 & 54.64 \\
Provides early-warning about a schedule & 99 & 54.09 \\
Increases project success & 97 & 53.00 \\
It is increases productivity & 83 & 45.35 \\
Other & 10 & 5.40 \\
\hline
\end{tabular}

The data in Error! Reference source not found. shows that EVA has made significant contributions to project executives in project management activities such as providing early warning about cost and integrating cost and schedule in practice as in the literature.

The opinions of managers using EVA support this claim. General thoughts of the participants who prefer to use EVA are given in Error! Reference source not found..

Table 8: Thoughts about EVA

\begin{tabular}{lcc}
\hline \multicolumn{1}{c}{ Thoughts } & f & \% \\
\hline It is useful for most projects & 84 & 45.90 \\
It is an extremely useful system & 58 & 31.69 \\
It is suitable for some projects & 35 & 19.13 \\
It is a system worth trying & 6 & 3.28 \\
It is not worth the effort & 0 & 00 \\
\hline
\end{tabular}

When Error! Reference source not found. is analyzed, it is seen that most of the participants have positive opinions about EVA. The most striking point is that none of 183 participants preferring to use EVA think that EVA is not worth the effort. This indicates that the EVA is indeed a beneficial system.

To evaluate how these preferences of executives using EVA affect the performance of the projects they carry out, the participants who measured the performance of their projects were divided into two according to whether they used EVA or not, and whether this situation had an impact on the projects carried out was examined. Accordingly, data on the performances of the projects carried out by the participants were collected. For this process, the 5-point Likert scale, which includes seven performance criteria, was used. The scale was analyzed for reliability, and it was found to have 0.811 Cronbach's Alpha coefficient. In addition, the item analysis showed that the questions on the scale were related to each other and should not be removed from the scale. Thus, it was understood that the internal consistency of the scale was at a good level. The criteria forming the project performance scale are given in Error! Reference source not found..

Table 9: Performance Variables

\begin{tabular}{cl}
\hline Variables & Explanation \\
\hline V1 & The ability of projects to reach milestones on time \\
V2 & The ability of projects to complete on a planned schedule \\
V3 & The ability of projects to complete on a planned budget \\
V4 & The ability of projects to meet customer expectations \\
V5 & The ability of projects to adapt to scope change \\
V6 & The ability of projects to meet the required safety conditions \\
V7 & The ability of projects to keep risks under control \\
\hline
\end{tabular}

Scale data were subjected to a normality test to choose the right method for the analysis. Both Kolmogorov-Smirnov and ShapiroWilk tests indicate that the data are not normally distributed. In addition, the histogram views of the data and the Q-Q curves show that the data is not normally distributed. Based on the determination that the data are not normally distributed, the analysis was carried out with the Kruskal-Wallis test. The results obtained are listed in Error! Reference source not found. 
Table 10 Mann-Whitney Test Sequence Rankings

\begin{tabular}{|c|c|c|c|}
\hline Variables & Use of EVA & Mean Rank & Sum of Ranks \\
\hline \multirow{2}{*}{ V1 } & Yes & 218.28 & 37980.00 \\
\hline & No & 190.57 & 43830.00 \\
\hline \multirow{2}{*}{ V2 } & Yes & 217.14 & 37782.50 \\
\hline & No & 191.42 & 44027.50 \\
\hline \multirow{2}{*}{ V3 } & Yes & 195.27 & 33977.50 \\
\hline & No & 207.97 & 47832.50 \\
\hline \multirow{2}{*}{ V4 } & Yes & 204.16 & 35523.50 \\
\hline & No & 201.25 & 46286.50 \\
\hline \multirow{2}{*}{ V5 } & Yes & 208.79 & 36329.50 \\
\hline & No & 197.74 & 45480.50 \\
\hline \multirow{2}{*}{ V6 } & Yes & 205.03 & 35675.00 \\
\hline & No & 200.59 & 46135.00 \\
\hline \multirow{2}{*}{ V7 } & Yes & 213.78 & 37197.00 \\
\hline & No & 193.97 & 44613.00 \\
\hline
\end{tabular}

When Error! Reference source not found. is analyzed, it is seen that participants who use EVA have higher rank means than those who do not use EVA in the majority of project performance criteria. Mann-Whitney U test results showing the significance of the difference between these two groups are given in Error! Reference source not found..

Table 11: Effect of EVA Usage on Project Success Factors (Mann-Whitney U Test)

\begin{tabular}{ccccc}
\hline Variables & Mann-Whitney U & Wilcoxon W & Z & Sig. (2tailed) \\
\hline V1 & 17265.0 & 43830.0 & -2.606 & .009 \\
V2 & 17462.5 & 44027.5 & -2.383 & .017 \\
V3 & 18752.5 & 33977.5 & -1.152 & .249 \\
V4 & 19721.5 & 46286.5 & -.279 & .780 \\
V5 & 18915.5 & 45480.5 & -1.034 & .301 \\
V6 & 19570.0 & 46135.0 & -.411 & .681 \\
V7 & 18048.0 & 44613.0 & -1.828 & .068 \\
\hline
\end{tabular}

The Mann-Whitney $\mathrm{U}$ test outcomes in Table 11 show that there is a significant difference at the level of 0.01 in V1 and 0.05 in V2, while there is no significant difference between the participants who use and do not use EVA in other criteria.

When the first and second variables where the significant difference was detected were examined, the fact that the participants who used EVA had higher rank means than the participants who did not use it is an indication of the positive effect of using EVA on the project performance. This indicates that the success of reaching milestones on time and completing the project on time is higher in projects using EVA than those who do not.

\section{CONCLUSION}

Day by day projects are getting more complex and this fact pushes managers to use new techniques in project management. However, this should not mean that traditional project constraints lose their importance. Even today the concept of time intensifying competitive environment has brought a much more important position. The fact that $74.34 \%$ of the participants consider the time constraint very important is an indicator of this state. Therefore, although EVA is a traditional project management tool, it continues to be one of the most effective methods in project management.

In this study, project management tendencies were examined, it was seen that the most time and cost metrics among the project performance metrics, the most preferred project calendar and project budget among the project management tools, and the Microsoft Project software among the project management software. In addition, the participants who measure the project performance were divided into two groups as those who use EVA and those who do not, and the project performances of the groups were compared, a significant difference was found between the two groups in terms of the performance criteria of reaching the milestones of the projects on time and completing the projects on time. When the average of the series of these criteria is examined, the group using the EVA has a better performance than the group that does not. This shows that it is possible to reach the milestones on time and complete the project on time using EVA. 
When considering the findings obtained, EVA is one of the most important and effective tools for project management. Therefore, it is thought that project executives using EVA will have the opportunity to gain a competitive advantage. However, the fact that the EVA method does not consider the risks and uncertainties is the most serious problem. Studies should be done to solve this problem, and the EVA technique should be made a more effective method.

\section{REFERENCES}

Anbari, F. T. (2003). Earned value project management method and extensions. Project Management Journal, 34(4), 12-23.

Bhosekar, S. K., \& Vyas, G. (2012). Cost controlling using earned value analysis in construction industries. International Journal of Engineering and Innovative Technology, 1(4), 324-332.

Chen, H. L., Chen, W. T., \& Lin, Y. L. (2016). Earned value project management: improving the predictive. International Journal of Project Management, 34(1), 22-29.

Chen, M. T. (2008). The ABCs of earned value application. 2008 AACE International Transactions, 1-9.

Gupta, R. (2014). Earned value management system. International Journal of Emerging Engineering Research and Technology, 2(4), $160-165$.

Kerzner, H. (2006). Project management: a systems approach to planning, scheduling, and controlling. Hoboken: Jhon Wiley And Sons.

Navon, R., \& Sacks, R. (2007). Assessing research issues in automated project performance control (APPC). Automation in Construction, 4(16), 474484.

Taylor, J. (2006). A survival guide for project managers. New York: Amacom.

Vandevoorde, S., \& Vanhoucke, M. (2006). A comparison of different project duration forecasting methods using earned value metrics. International Journal of Project Management, 24(4), 289-302.

Zhong, S., \& Wang, X. (2011). Improvement and application of earned value analysis in coal. First International Symposium on Mine Safety Science and Engineering. 26, pp. 1983-1989. Beijing: Procedia Engineering.

\section{Annex: Survey Form}

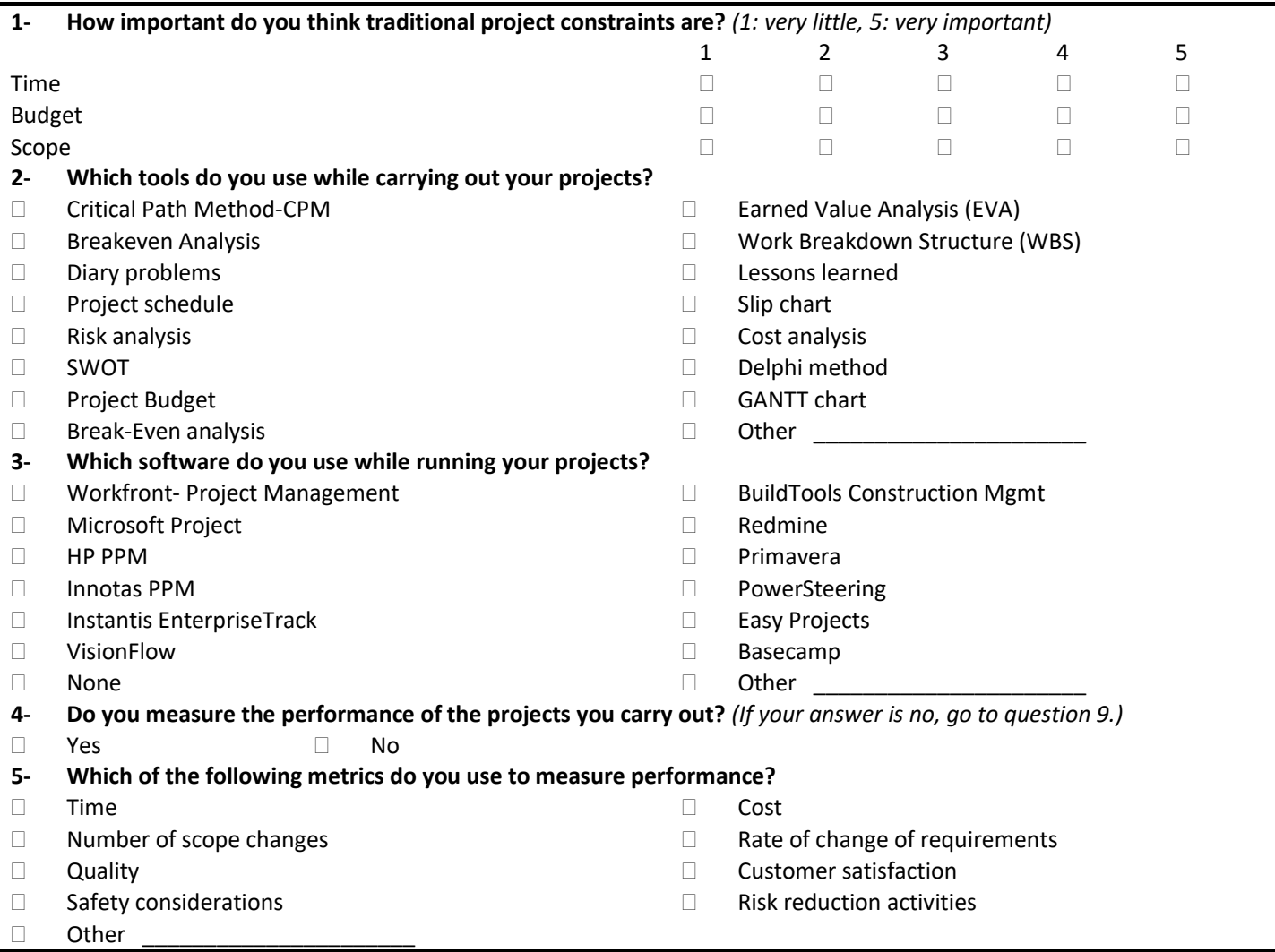


6- What is the success level of your projects? (1: very bad, 5: very good)

Reaching milestones on time

Completion at the scheduled time

Completion with planned budget

Ability to meet customer expectations

Ability to adapt to scope changes

Ability to provide security conditions

Ability to control risks

7- How do you monitor project costs?

With Earned Value Analysis

With internal data

1

1

2

2

$\square$

$\square$

$\square$$$
\square
$$$$
\square
$$

With external data

With integrated data

I am a little familiar

I am not familiar

8- How much do you know about earned value analysis?

Expert

Knowledgeable

Sounds familiar

9- Do you use earned value analysis techniques in your projects?

(If your answer is No, go to question 13. If your answer is Yes, do not answer question 13.)

Yes $\quad \square \quad$ No

10- Which type of projects do you use the earned value analysis system?

Several pilot projects $\quad \square \quad$ Large and critical projects

11- What is your opinion about the earned value analysis system?
$\square$ Extremely helpful
Suitable for some projects
$\square$ Useful for most projects
Can be tried

12- What are the contributions of earned value analysis to your project management activities?

Offers valuable numerical data

Provides early warning of cost

Provides early warning of calendar

Increases project success

13- Why don't you use the earned value analysis system?

The lack of a suitable system for the industry

Not having the necessary technical knowledge

about the system

It is not considered to work

The tediousness of collecting and processing data

Top management does not support

It's a failed system

Other reasons

Integrates cost and schedule

Analysis results shed light on similar projects

Increases productivity

Other

Customers have no such demand

Not wanting to change the current control system

It's a costly system

The system has too many rules

It's a complicated system

Lack of technological infrastructure 